\title{
A saúde do trabalhador e a (des)proteção social no capitalismo contemporâneo
}

\author{
Aurora Marcionila de Assunção Ferreira \\ Hospital das Clínicas da Universidade Federal de Pernambuco \\ (UFPE)
}

\author{
Angela Santana do Amaral \\ Universidade Federal de Pernambuco (UFPE)
}

\begin{abstract}
A saúde do trabalhador e a (des)proteção social no capitalismo contemporâneo
Resumo: Este artigo é resultado de uma pesquisa que analisa as determinações sociais do afastamento dos trabalhadores acometidos por acidentes de trabalho ou doenças ocupacionais e sua relação com as novas exigências do mundo produtivo, que resulta na perda da sua capacidade de trabalho e da saúde, colocando-os na condição de desprotegidos. A investigação foi fundamentada no aporte teóricometodológico da teoria social crítica, com ênfase na abordagem qualitativa, revisão da literatura sobre o tema e a realização de entrevistas semiestruturadas com dez trabalhadores que vivenciam a problemática do estudo, no período de 2010 a 2012. Os resultados evidenciaram a existência de mecanismos que são levados a cabo pelo Estado com fortes impactos na saúde dos trabalhadores.

Palavras-chave: Trabalho. Saúde. Força de trabalho. Proteção Social. Seguridade Social.
\end{abstract}

\section{Workers Health and the Lack of Social Protection in Contemporary Capitalism}

Abstract: This article is the result of a study that analyzed the social determinations of workers who are absent because of work accidents or occupational illness and the relation of this process with the new demands of the productive world, which results in the loss of their capacity to work and in debilitation of their health, leaving them in an unprotected condition. The theoretical-methodological support for the study is critical social theory. A review of the literature about the issue was conducted. Semi-structured interviews were realized with ten workers who experienced the problematic examined in the study from 2010-2012, which were analyzed with a qualitative approach. The results indicate the existence of mechanisms that are exercised by the state that have a strong impact on worker health.

Keywords: Work. Health. Labor force. Social protection. Social Security. 


\section{Introdução}

O desgaste da força de trabalho ${ }^{1}$ é um produto sócio-histórico inerente ao sistema capitalista que, ao longo das suas permanentes reatualizações para expandir os lucros e se manter como modo de produção dominante, criou estratégias e formas de produzir mercadorias que intensificaram o trabalho e potencializaram a sua exploração.

Na dinâmica histórica capitalista, particularmente nas suas formas de cooperação, manufatura e grande indústria, pode-se notar que os mecanismos de extração da mais-valia se configuraram como uma operação capaz de impulsionar a expansão do modo de produção capitalista com o objetivo da acumulação e, assim, manter a vitalidade necessária para a reprodução do capital. Ao mesmo tempo, tais mecanismos produziram elevados níveis de exploração do trabalhador que, inevitavelmente, levaram ao desgaste da sua força de trabalho e rebateram nas condições da sua saúde e, portanto, na sua reprodução. Ao explicar o processo de exploração a partir do desgaste da força de trabalho com a intensificação do ritmo e ampliação da jornada para produção da mais-valia, Marx (2011) identificou que a apropriação do trabalho excedente não produz apenas a atrofia da força humana de trabalho, quando retira suas condições regulares, morais e físicas das atividades e do seu desenvolvimento, como também, promove o esgotamento da força de trabalho de forma prematura, ao diminuir o tempo de trabalho socialmente necessário e aumentar o trabalho excedente. Isso contribui para a diminuição do tempo de vida que tal força de trabalho poderia produzir ao longo da vida do trabalhador.

No capitalismo contemporâneo, as transformações no mundo do trabalho trazem sérias consequências para a saúde dos trabalhadores, contribuindo para o aumento do desgaste da força de trabalho, precarização e retração dos direitos historicamente conquistados pelos trabalhadores, a partir dos meados da segunda metade do século 20, particularmente nos países centrais.

Nos países capitalistas periféricos, este processo de mudanças possui particularidades que, todavia, não ficaram imunes à crise capitalista e foram atingidos no âmbito da produção e da reprodução social. Desemprego, flexibilização das relações de trabalho, informalidade, precarização do trabalho, regressão dos direitos sociais são algumas características presentes durante mais de três décadas de crise, sob a orientação dos preceitos dos organismos financeiros internacionais.

Neste movimento, o capital reorganizou todas as esferas da vida social. Para Mota e Amaral (2008), o capital, passou a intervir de diferentes formas, em três esferas principais: na produção, através do aumento da taxa do lucro com o crescimento da produtividade do trabalho, articuladas às novas tecnologias que são inseridas nesse espaço e à forma de consumir a força de trabalho; na circulação, forjando mudanças no mercado consumidor, emergindo, daí, novos tipos de concorrência entre as empresas e na qualidade dos produtos; na área sócio-política e institucional, através de um novo controle sobre o trabalho, promovendo reformas nas instituições e estratégias capazes de incorporar às mudanças o consentimento e a adesão dos trabalhadores.

A reestruturação produtiva do capital, naqueles países, implicou o surgimento de novas exigências para a classe trabalhadora, configurando uma nova morfologia do trabalho ${ }^{2}$ que acentuou as suas precárias condições de saúde e reprodução.

Nessa nova configuração do espaço produtivo, as consequências para a saúde dos trabalhadores são produzidas pelas determinações histórico-ontológicas do capital e complexificadas com o aparecimento de novas formas de adoecer e morrer dos trabalhadores. A proteção social, então, para atender às necessidades dos trabalhadores, quando da perda da sua saúde no trabalho é efetivada de acordo com as requisições do processo produtivo flexibilizado, o qual tem sido tensionado por uma brutal regressão dos direitos do trabalho.

É no contexto de tais reflexões que este artigo procura analisar a problemática do afastamento do trabalhador que tem a sua saúde comprometida em face dos processos de trabalho contemporâneos e também das mudanças operadas no âmbito da política de Seguridade Social, as quais vêm sendo desconstruídas com o assentimento do Estado brasileiro.

\section{A pesquisa: sujeitos envolvidos, problemática do estudo e procedimentos metodológicos}

O suposto da pesquisa inscreve-se na relação entre as formas do trabalho contemporâneo e a implementação dos direitos de Seguridade Social, considerando que estas mediações interferem na reinserção do trabalhador ao mercado de trabalho e se vinculam às determinações sociais mais amplas que dizem respeito à forma como se organiza a sociedade capitalista face à configuração que os processos de trabalho assumem no padrão de acumulação do capital em sua crise estrutural, com a participação ativa do Estado.

O estudo foi desenvolvido no espaço sócio-ocupacional de saúde, em hospital universitário, com trabalhadores afastados de suas atividades para tratamento relacionado a lesões e limitações físicas adquiridas no trabalho e na condição de segurados da Previdência Social. O interesse em realizar a pesquisa nesse espaço se 
justificou pela necessidade de problematizar algumas questões que demandavam respostas por parte dos profissionais do Serviço Social e a escolha do tema, dentro desse contexto, instigava o aspecto mais relevante das demandas: a insuficiência de alternativas para assegurar a proteção social aos trabalhadores que perderam a sua saúde no processo de trabalho.

Identificamos que o trabalhador, em momento de menor capacidade produtiva pela perda da sua saúde no trabalho, necessita de afastamento para o tratamento. Neste cenário, o trabalhador assalariado formal que ultrapassa o tempo recomendado para um determinado tratamento confronta-se com um conjunto de problemas para conseguir manter o seguro social enquanto trata da saúde e o que deveria ser constitutivo do direito consolidado, não consegue se efetivar, em termos de responder às suas necessidades. O resultado disso é que acaba havendo uma transferência de responsabilidades da Saúde para a Previdência Social e vice-versa, evidenciando-se uma clara desarticulação das políticas e uma maior dificuldade para a garantia do direito.

$\mathrm{Na}$ tentativa de descortinar as reais causas dessa situação social sustentamos que o conhecimento necessário para apreender as relações contidas no nosso objeto de estudo só seria possível a partir de um método de análise que permitisse articular as diversas determinações da realidade. Assim, a totalidade social, expressa na relação saúde-proteção social, somente poderia ser capturada no movimento entre a singularidade do objeto, a sua particularidade e a relação com a universalidade.

Desse modo, os procedimentos metodológicos acionados para aproximação e sistematização da problemática tiveram como ponto de partida uma revisão de literatura de autores que discutem, sob uma perspectiva histórico-dialética, a temática da saúde do trabalhador e sua relação com a proteção social na dinâmica capitalista contemporânea.

A operacionalização da pesquisa se efetivou mediante a realização da técnica de entrevista social semiestruturada aplicada com dez trabalhadores escolhidos de acordo com os critérios da problemática, considerando o período de 2010 a 2012. O conteúdo da entrevista privilegiou perguntas fechadas e abertas, com um roteiro norteador que permitisse identificar a maneira como os trabalhadores vivenciam a situação de desemprego/afastamento; as principais dificuldades encontradas para o tratamento e para a garantia do direito previdenciário; a expectativa de retorno ao trabalho; as respostas às demandas do contexto do tratamento de saúde e do direito social e as formas de enfrentamento dos trabalhadores para a garantia da proteção social.

Optamos por uma abordagem qualitativa que possibilitasse a análise das questões referentes à forma como o trabalhador se insere e vivencia as suas experiências de trabalho e como atendem as suas necessidades de reprodução. Procuramos, ainda, identificar na complexidade do mundo produtivo, as novas demandas e exigências para a reprodução da força de trabalho e as formas como as políticas de saúde e da previdência operam nesse contexto.

$\mathrm{Na}$ análise dos dados, procuramos evidenciar as articulações teórico-metodológicas capazes de compreender a proteção social construída na sociedade capitalista brasileira, através de políticas sociais, especialmente a Seguridade Social e sua interface com a saúde do trabalhador.

A pesquisa cumpriu todos os princípios éticos envolvendo seres humanos, com Parecer consubstanciado do Comitê de Ética e Pesquisa do Centro de Ciências da Saúde da Universidade Federal de Pernambuco, sob o número 214.095, com TCLEs entregues e assinados e relatório final aprovado sob o número 366.366 de 23 de agosto de 2013, sem pendências ou recomendações.

\section{Constituição do Estado brasileiro, políticas de proteção social e desconstrução dos direitos sociais}

Ao tratar da economia brasileira após os anos 1930, Oliveira (2011) ressalta que a dinâmica econômica desse período possui particularidades que demarcam o fim da hegemonia de uma base agrário-exportadora e o predomínio de uma base urbano-industrial na estrutura produtiva. Conforme o autor, dentre as circunstâncias históricas desse desenvolvimento foi necessário fortalecer um modo de acumulação que substituísse o acesso externo da economia agrário-exportadora, colocando as novas classes burguesas empresário-industriais em posição hegemônica. Nesse contexto, a inserção dessas novas classes não excluíram totalmente as classes proprietárias rurais, o que permitiu a mistura de modelos arcaicos e modernos na organização da produção e do trabalho e que serviram adequadamente para a expansão do capitalismo global.

Sob essas condições, e da forma como se processou o desenvolvimento industrial no país, a precarização e a exploração dos trabalhadores assalariados foram traços marcantes. A proteção social edificada para o enfrentamento do desgaste da força de trabalho, nesse contexto, foi construída mediante as legislações do trabalho e respondiam, em larga medida, pela necessidade do Estado de organizar a economia, mediando os conflitos entre o capital e o trabalho no espaço da produção industrial. 
As conquistas que se formaram em torno dos direitos para o trabalho, através das lutas que se fortaleceram com as discussões nas fábricas e o surgimento dos sindicatos dos trabalhadores, além da influência político-ideológica dos imigrantes europeus não foram suficientes para uma experiência da proteção social para os trabalhadores, no Brasil, que alcançasse o patamar do que se chamou de Estado de bem-estar social dos países centrais, resumindose em algumas conquistas para os direitos do trabalho e políticas sociais de caráter não universal ${ }^{3}$.

Dessa forma, o processo de desenvolvimento capitalista no Brasil cumpriu seu papel na estrutura do capitalismo mundial, integrando-se subordinadamente à expansão do capital.

Os sinais mais significativos que concorreram para as mudanças no mundo do trabalho se explicitaram a partir da reestruturação produtiva dos anos 1970 e na particularidade brasileira, nos anos 1990, período histórico no qual o país consolidava o Estado democrático de direito, momento em que a promulgação da Constituição Brasileira de 1988 afirmava um legado de direitos tanto no âmbito do trabalho como na Seguridade Social, apesar da preservação da propriedade privada. Essas conquistas, resultado do movimento organizado da classe trabalhadora e de diversos segmentos da sociedade civil, se processaram num momento de transição de ditadura para democracia com o aprofundamento do caráter das lutas pela redemocratização do Brasil e, no campo da saúde, havia uma forte influência do movimento de reforma sanitária brasileira.

A política para a saúde que foi legitimada com a nova Constituição estabeleceu em seus princípios a "universalidade do acesso, integralidade das ações e equidade" com a garantia do dever do Estado para sua efetivação (BRASIL, 1988), em contraposição à lógica biomédica que vinha sendo desenvolvida no Brasil anterior à Constituição. Nesse contexto, o SUS integrou a Política de Saúde do Trabalhador que, acompanhando as mesmas determinações históricas em que se desenvolveu o percurso da luta pela saúde através do movimento de reforma sanitária brasileira e da saúde coletiva, demarcou o início da luta pela política no Brasil, no final dos anos 1970.

Contudo, ao mesmo tempo em que a sociedade brasileira esboça sua constituição cidadã, nos países centrais já se aplicavam as medidas de ajustes neoliberais que se disseminavam para todas as nações capitalistas. Estes ajustes tinham seu foco nas modificações do processo produtivo, no mundo do trabalho e na destruição dos direitos sociais conquistados historicamente pelos trabalhadores. No Brasil, as mudanças constitucionais nas políticas de trabalho e de saúde têm seu marco no início dos anos 1990, sob as orientações dos organismos econômicos multilaterais.

Esse contexto estava na base da reestruturação produtiva no Brasil que, conforme discutiram Mota e Amaral (2008), expressava-se através de um movimento internacional direcionado pela globalização e disseminação do pensamento neoliberal, tendo como elementos ideológicos norteadores a competência e a eficiência do setor privado, a retirada estratégica do Estado para as políticas de proteção ao trabalho, ao emprego e às parcerias do capital com o trabalho, consolidando, dessa forma, a propagação de ideias e valores que desqualificavam as demandas e conquistas históricas dos trabalhadores.

Nessa dinâmica, o processo de mudanças no mundo do trabalho no Brasil foi se desenvolvendo gradualmente impulsionado pela atuação do Estado. Desde então, ao combinar traços do modelo fordista com os da acumulação flexível, podemos identificar novas manifestações de doenças e acidentes relacionados ao mundo do trabalho, em face das novas exigências para os trabalhadores.

No contexto brasileiro, uma das principais marcas da nova morfologia do trabalho é a precarização. Com base nos estudos de Alves (2011), Antunes (2013) e Druck (2013), a precarização se apresenta nos espaços produtivos do emprego, da informalidade e do desemprego, e não escolhe o tipo de trabalhador ou sua posição de acordo com o nível de capacitação e potencialidade. Produz a violência moral, ética, política, física e psíquica do trabalhador, sendo uma das marcas do modelo de acumulação flexível. A condição para a sua materialização é dada pela instabilidade, insegurança, intensificação dos ritmos, extensão da jornada de trabalho, fragmentação de classe e a concorrência entre os próprios trabalhadores. "Uma precarização que atinge a todos indiscriminadamente e cujas formas de manifestação diferem em grau e intensidade, mas têm como unidade o sentido de ser ou estar precário numa condição não mais provisória, mas permanente" (DRUCK, 2013, p. 56).

Nessas análises, as formas precárias de trabalho e emprego são compreendidas como sendo forjadas por fatores predominantes na desestruturação do trabalho no mercado e no papel que o Estado assume em relação às políticas sociais, gerando uma desproteção social que vai ter impactos sobre a saúde dos trabalhadores e a sua reprodução.

\subsection{A desarticulação da Seguridade Social e as tendências de retração dos direitos sociais}

As determinações que atuam no sentido de limitar a efetivação da Política de Seguridade Social encontram suas raízes nas diretrizes internacionais de organismos multilaterais que passam a indicar as mudanças necessárias no âmbito da proteção social. 
Tais mudanças, na esfera dos estados nacionais, são operadas pelas frações locais da burguesia que implementam o seu projeto articulado às novas determinações de restauração do capitalismo mundial. As indicações gerais se localizam na tendência da mercantilização dos direitos sociais e no seu redirecionamento a parcelas específicas da sociedade. No campo da saúde, o que se observa nessas três últimas décadas é um profundo desmonte do sistema, apesar das lutas de resistência.

Sob tais condições, afigura-se a tendência de aprofundar a fragmentação e ressignificar o caráter de universalidade, através de propostas jurídico-políticas que se adaptam e conferem legitimidade a essas mudanças, configurando uma realidade que aposta na desregulamentação dos direitos sociais contidos na Política de Seguridade Social, sob o comando do Estado. Para Boschetti (2009), a reorganização e a reestruturação da Política de Seguridade Social e sua articulação na realidade brasileira tiveram um caráter inovador; no entanto, a intenção de constituir uma ampla proteção social foi dando lugar a um sistema híbrido que contempla direitos derivados e dependentes do trabalho, como é o caso da previdência, direitos de caráter universal, como a saúde, e direitos seletivos, de que é exemplo a assistência. Para a autora, as diretrizes institucionais da forma da lei não foram totalmente materializadas, resultando um padrão de seguridade social que não cumpriu uma articulação capaz de dar respostas à proteção ao trabalhador de forma integral.

À ausência desta integração, identificamos, no âm-

\section{... 0 adoecimento no trabalho é}

parte das condições sócio-

\section{históricas que se apresentam}

na realidade em que se

desenvolve a reprodução

material e espiritual... bito da saúde, nosso objeto de pesquisa, a falta de respostas dos serviços públicos às necessidades de saúde, especialmente no momento em que se vê comprometida a capacidade produtiva do trabalhador e este necessita da proteção social. Do ponto de vista da atenção à saúde, também podemos constatar que o tratamento se torna inviabilizado em função da inexistência de uma estrutura física adequada à demanda e a condições básicas que são reveladas, por exemplo, em grandes filas de espera para a realização de um tratamento médico ou cirúrgico. $\mathrm{Na}$ área da Previdência Social, destacamos as dificuldades que têm os trabalhadores inseridos em relações precarizadas de trabalho e no mercado informal para acessar os benefícios previdenciários ou para mantê-los, quando da continuidade da incapacidade. Na área da Assistência Social, o Estado passa a operar predominantemente com programas de alívio à pobreza como alternativa ao enfrentamento do desemprego.

Essas constatações são apoiadas nos estudos de Mota (2008), ao afirmar que os segmentos da política de Seguridade Social no Brasil não se articulam no sentido de formar um efetivo sistema de proteção; ao contrário, enquanto avança a mercantilização e a privatização da Saúde e da Previdência, é promovida uma ampliação na Assistência Social, como um novo fetiche de combate à desigualdade social, transformando-se no principal segmento de proteção social. As tendências se voltam para as ações compensatórias e de inserção que, nos princípios originários da política, surgem para as pessoas que não têm como prover o seu sustento através do trabalho e "impõem novas condicionalidades de acesso aos benefícios sociais e materiais nos casos de afastamento do trabalho por doenças, acidentes, invalidez e desemprego temporário" (MOTA, 2008, p. 137).

\section{Entre o trabalho e a garantia de direitos: tensões e tendências para a saúde do trabalhador}

Trataremos aqui da análise dos dados e resultados da pesquisa a partir das entrevistas com os trabalhadores, entendendo que o adoecimento no trabalho é parte das condições sócio-históricas que se apresentam na realidade em que se desenvolve a reprodução material e espiritual, nos termos de Marx. Tais condições se modificam na sociedade capitalista contemporânea, embora permaneçam as determinações em que estas se fundam: a exploração do trabalho.

Com base nas entrevistas, apreendemos o perfil dos trabalhadores, articulando, nesse contexto, as suas experiências a partir de sua realidade e das implicações em relação a sua reprodução.

Identificamos que neste perfil estão presentes algumas características que inserem os trabalhadores em diferentes espaços de criação de valor para o capital e, ainda que as profissões não exijam maiores complexidades - na sua maioria, estavam vinculadas a trabalho simples e de muito esforço físico -, os processos, as formas e as requisições para o trabalho se alteram para responder às necessidades do capital. Baixa escolaridade, renda mínima, idade considerada de envelhecimento para o capital, trabalho pesado, polivalente e repetitivo, 
posições inadequadas, trabalho insalubre/perigoso e extensas jornadas de trabalho, constituem traços comuns aos entrevistados, conforme os depoimentos a seguir:

Eu era considerado um trabalhador ativo e muito atento às atividades; porém pegava muito em peso, garrafões de água, caixas pesadas e numa dessas vezes, desloquei o ombro e nunca mais fiquei bom para trabalhar. A idade também pesou (Entrevistado 2).

Eu trabalhava recolhendo lixo; correndo de lá pra cá, embaixo de sol quente e chuva, sentindo mau cheiro o tempo todo. Pegava em sacos pesados e sujos e tinha que ser rápido para dar tempo de seguir o caminhão (Entrevistado 4).

Eu trabalhava como auxiliar de cozinha. Além de cozinhar, deslocava panelas pesadas, lavava pratos etc. Gostava de fazer o trabalho, apesar de achar que tinha muitas exigências de vários serviços ao mesmo tempo. Gostava de cozinhar e acho que as exigências do meu trabalho me deixaram com pouca condição física (Entrevistada 5).

Grande parte dos entrevistados considerou que sua posição no espaço produtivo se relacionava ao desenvolvimento de trabalhos que exigiam longas jornadas requerendo o exercício de muitas funções e grande dispêndio físico. As pressões no ambiente de trabalho e as formas precarizadas de sua execução se tornam, nesse contexto, uma ameaça direta ao desgaste da força de trabalho de forma prematura.

As características apresentadas pelos trabalhadores da pesquisa, em termos gerais, conformam o que Antunes (2005) chamou de "os subproletários do mundo moderno, fabril e de serviços". De acordo com Lara e Canoas (2010), a representação desses trabalhadores se dá ainda através do trabalho feminino mal remunerado, pelos jovens que não conseguem ingressar no mercado de trabalho por pouca experiência e pelos trabalhadores considerados em idade de envelhecimento para o capital no contexto atual do seu desenvolvimento, aumentando a massa de desocupados. Esses aspectos também são reforçados quando analisamos a idade e a escolaridade dos trabalhadores: os 10 trabalhadores da pesquisa apresentaram idade acima dos 34 anos, predominando a faixa etária de 39 a 43 anos e para a escolaridade, predominou o Ensino Fundamental incompleto.

A grande competitividade do mercado de trabalho intensifica o aumento do desemprego entre os menos qualificados. Os trabalhadores que estão na faixa dos 40 anos de idade ou mais e que, historicamente, exerceram funções num mesmo ramo industrial ou mesmo com maior dispêndio físico (LARA; CANOAS, 2010), tornam-se deslocados dos novos conceitos da produção flexível que exigem maior qualificação e competição no atual mercado de trabalho. Considerados descartáveis para a produção quando não possuem a capacidade total de sua força produtiva, pelo desgaste produzido pelo trabalho excedente, esses trabalhadores confirmam o que já avaliava Marx (1996, p. 271) "O consumo da força de trabalho pelo capital é tão rápido que o trabalhador de mediana idade, na maioria dos casos, já está mais ou menos esgotado. Ele cai nas fileiras dos excedentes ou passa de um escalão mais alto para um mais baixo."

Tomamos como exemplo os seguintes depoimentos:

A empresa já disse que não tem outra função para mim. Não quero ser rebaixado de posto. Só se conseguir outro emprego; mas, como, desse jeito que estou agora? (Entrevistado 2).

A empresa já me disse que não tem mais lugar pra mim, que tentasse falar com o médico para me aposentar (Entrevistado 9).

Sob essas condições, entendemos que o lugar desses trabalhadores favorece a possibilidade de tornarem-se desnecessários para as empresas e serem facilmente substituídos face às exigências do modelo de produção, da força sobrante para o mercado e do desgaste de sua força de trabalho. Nos termos de Marx, esses trabalhadores são considerados o peso morto para o capital.

Na maioria dos discursos dos entrevistados apareceu a questão da reprodução do trabalhador e da sua família, que se deu a níveis mínimos no momento do afastamento, sendo o benefício acidentário a única alternativa de que dispunham para fazer face às suas necessidades de subsistência, conforme os relatos a seguir:

Fiz cirurgia de amputação da perna e uso prótese. Depois da cirurgia me separei da mulher e precisei ajudar 2 filhos pequenos; moro em lugar de ladeira e tenho dificuldade para andar e recebo muito pouco pelo benefício; também não faço nenhum trabalho para ajudar na renda. Desestruturei minha vida e o meu trabalho por causa desse acidente (Entrevistado 1). 
Desde o acidente não tenho condições para o trabalho. Minha família é grande, a situação é muito difícil e estou com o benefício cortado há quatro meses, vivendo da ajuda da família e tentando voltar o benefício. Estou muito preocupado com o sustento da minha família e me sentindo humilhado de ter que precisar dos outros, pois sou um homem que poderia estar sustentando a minha família se não fosse o acidente que sofri no trabalho (Entrevistado 2).

Sinto muito medo do futuro, medo de não ficar boa e não conseguir sustentar minha família. O acidente mudou minha vida, mudou totalmente a forma como eu vivia antes. Não consigo me ver trabalhando novamente nas condições de antes (Entrevistado 6).

Identificamos que os trabalhadores dessa pesquisa vivenciam mais intensamente as expressões da questão social, a partir da desestruturação das suas vidas e do seu núcleo familiar no momento do afastamento do trabalho. O cotidiano de vida modifica-se em torno da inexistência de perspectiva de experimentar o trabalho nas mesmas condições anteriores à perda de sua capacidade produtiva. Percebe-se a importância que o trabalho tinha na vida dos entrevistados, na medida em que se referem à desconstrução de suas relações sociais a partir da impossibilidade de sua execução.

Sentimentos como falta de perspectiva, medo e humilhação passam a fazer parte do cotidiano e das formas de viver esse tempo pós-acidente. O retorno ao trabalho em condições satisfatórias é visto quase como uma impossibilidade e a falta do trabalho, como elemento estruturador da sociabilidade, impacta fortemente a reprodução dos trabalhadores.

Destacamos os seguintes relatos dos trabalhadores em sua experiência com a empresa após o afastamento do trabalho:

Acho que a empresa não me quer mais. É muito diferente, eu sinto que não sirvo mais e parece que nem fiz parte daquilo (Entrevistado 2).

Eu tenho muito medo de perder o benefício e ter que voltar a trabalhar sem condições ou então ficar na empresa pela obrigação do acidente até perder a estabilidade, sendo tratado como um estorvo (Entrevistado 5).

A problemática do afastamento do trabalhador no momento de menor capacidade produtiva está diretamente relacionada com a necessidade de reprodução e reparação da perda da saúde para o trabalho. A via crucis posta aos trabalhadores para assegurar seus direitos é potencializada pelas exigências do mundo produtivo e pela falta de respostas articuladas da Política de Seguridade Social, a exemplo dos seguintes depoimentos:

A empresa acha que o INSS está forçando a volta ao trabalho por já passar mais de 2 anos de afastamento e acha que eu não tenho condições para voltar. Aí, nem a empresa me aceita, nem o INSS quer que eu continue no benefício (Entrevistado 2).

Fiz uma cirurgia no ano passado, mas não fiquei totalmente bom para trabalhar com peso, me abaixar, melhorei só um pouco de como estava antes. Perdi tempo para me tratar. Esperei dez meses pra ser chamado pra cirurgia; mas também tinha que fazer fisioterapia e o exame de ressonância magnética que demorou muito para marcar. Ainda mais, tinha dificuldade pra marcar a consulta do médico daqui para pegar o laudo médico e entregar nas datas que o INSS pedia (Entrevistado 3).

Eu espero essa cirurgia desde 2010. Primeiro passou um ano e meio com o aparelho quebrado; quando consertaram, me chamaram para cirurgia; aí, faltou anestesista e a cirurgia foi suspensa duas vezes pelo mesmo motivo. O INSS tá cobrando uma data certa pra poder continuar o benefício, até já pedi um laudo pro médico dizendo isso, porque o INSS pensa que a gente está mentindo, que não quer fazer a cirurgia. Nessa história, a gente é que paga o pato (Entrevistado 9).

As problemáticas apresentadas pelos trabalhadores da pesquisa indicaram que, diante da diminuição de sua capacidade produtiva pela perda da saúde no trabalho, torna-se difícil a sua reinserção no mercado de trabalho. Em razão disso, os trabalhadores se inserem num contexto de precarização mais ampla, que envolve as esferas do trabalho, social e econômica e se constituem como aqueles considerados potencialmente inadequados às modernas exigências das empresas capitalistas e desprotegidos pelo Estado, quando os direitos derivados do trabalho deixam de ser uma realidade para reparar a perda da saúde no trabalho. 


\section{Considerações finais}

A ofensiva do capital sobre os direitos sociais tem suas raízes no projeto contrarreformista do Estado levado a cabo pelos setores dominantes para atender às necessidades do capital e, a partir desse processo, investiu na disseminação dos ajustes e medidas que redefiniram o conceito, as condições de acesso, as formas de financiamento, a cobertura, a abrangência e o público-alvo da Política de Seguridade Social. Portanto, mudanças no âmbito da produção e do Estado resultaram no redesenho dessa política, implicando uma regressão dos direitos dos trabalhadores no que se refere a sua proteção social.

Com essas mediações, a pesquisa mostrou que as dificuldades de reinserção dos trabalhadores ao mundo produtivo quando perdem ou comprometem a sua saúde no trabalho estão intimamente relacionadas com a nova configuração do trabalho na contemporaneidade: flexibilidade, precariedade, superexploração e desregulamentação das relações de trabalho são aspectos que deixam os trabalhadores mais vulneráveis sob o ponto de vista objetivo e subjetivo e, distantes do mercado, porque agora, suas condições físicas impedem seu retorno ao mundo do trabalho e a sua sociabilidade.

A pesquisa revelou, ainda, que as formas degradantes e extenuantes para o trabalho são utilizadas pelo capital para viabilizar as suas necessidades de desenvolvimento num cenário de profundas inovações tecnológicas, organizacionais e subjetivas. Nesse contexto, os trabalhadores de potencialidades consideradas desqualificadas para atender as demandas atuais podem, diante das circunstâncias, serem facilmente substituídos e descartados.

Dessa forma, o desgaste da força de trabalho somado às novas formas de expropriação do trabalho excedente constituem as bases para a superexploração do trabalhador e, nessa dinâmica, o seu descarte é materializado pela diminuição de sua capacidade produtiva.

Estes trabalhadores são sabedores de que a diminuição da sua capacidade produtiva não lhes permite mais, no atual contexto, um retorno ao mercado de trabalho em razão das novas exigências do processo produtivo. Resta-lhes, agora, a alternativa do benefício previdenciário e a proteção do Estado para que possam atender suas necessidades de subsistência e de reprodução.

A proteção social que, em tese, daria respostas a essa problemática, não é sustentada no campo do direito social, considerando que as limitações para a sua efetivação foram expressas nas falas dos trabalhadores. Nessa lógica, dificilmente os trabalhadores podem assegurar seus direitos, ainda mais quando encontram os serviços de saúde e previdência completamente desmontados, do ponto de vista da integralidade do atendimento. Também não se vislumbra qualquer alternativa pela via da construção de políticas de emprego, muito embora a Política Nacional de Saúde do Trabalhador preceitue a implementação de ações integradas da saúde, previdência e trabalho. Tais alternativas, longe de serem asseguradas pelo Estado colocam o trabalhador na condição de desprotegido. A tendência é a de que estes trabalhadores encontrem no âmbito da assistência a única possibilidade de terem algum tipo de proteção.

Percebemos, com essas mediações, que o processo de transferência de responsabilidades nos segmentos da saúde e da previdência impede a possibilidade de respostas efetivas para atender as demandas dos trabalhadores adoecidos no trabalho, quando são impostos limites para a efetivação do tratamento de saúde ao mesmo tempo em que se impõem dificuldades para a garantia do direito previdenciário.

Diante dessas considerações, percebemos que o horizonte para o enfrentamento de tais contradições pressupõe a necessidade de construir e fortalecer espaços de articulação política vinculados à defesa da saúde do trabalhador, buscando, incessantemente, compreender a problemática em seus fundamentos, enquanto práticas político-pedagógicas de prevenção, vigilância e de resistência coletiva dos trabalhadores para assegurar o direito universal à saúde, ao trabalho e à proteção social.

Diante disso, torna-se imperativo a renovação da luta de classes dos trabalhadores organizados como alternativa real para o embate necessário às fraturas que o capitalismo contemporâneo promove no sentido de desconstrução do trabalho, que tem sido a principal estratégia do capital em busca de sua expansão e vitalidade.

\section{Referências}

ALVES, G. Trabalho e subjetividade: o espírito do toyotismo na era do capitalismo manipulatório. São Paulo: Boitempo, 2011. ANTUNES, R. A nova morfologia do trabalho e o desenho multifacetado das ações coletivas. In: ANTUNES, R. (Org.). O caracol e sua concha: ensaios sobre a nova morfologia do trabalho. São Paulo: Boitempo, 2005, cap. 6, p. 75-83.

. A nova morfologia do trabalho e suas principais tendências. In: ANTUNES, R. (Org.). Riqueza e miséria do trabalho no Brasil II. São Paulo: Boitempo, 2013, parte I, p. 13-28.

BOSCHETTI, I. Produção e reprodução da vida social: a política da seguridade social no Brasil. In: Serviço Social: Direitos Sociais e Competências Profissionais. Brasília: Conselho Federal de Assistentes Sociais, 2009, p. 324-338. 
BRASIL. Constituição da República Federativa do Brasil. Promulgada em 5 outubro de 1988. (Título VIII, Capítulo II, Seção I, art. 194). Disponível em: <http://www.planalto.gov.br/ccivil_03/constituicao/constituicao.htm〉. Acesso em: 7 fev. 2014.

DRUCK, G. A precarização social do trabalho no Brasil. In: ANTUNES, R. (Org.). Riqueza e miséria do trabalho no Brasil II. São Paulo: Boitempo, 2013, parte I, p. 55-74.

LARA, R.; CANOAS, J. W. Trabalho, envelhecimento e desemprego. In: LOURENÇO, E. et. al. O avesso do trabalho II: trabalho, precarização e saúde do trabalhador. São Paulo: Expressão Popular, 2010, cap. 6, p. 137-157.

MARX, K. O capital: crítica da economia política. Tradução de Regis Barbosa e Flávio R. Kothe. São Paulo: Nova Cultural, 1996. (Livro 1. Tomo 2).

. O capital: crítica da economia política. Tradução de Reginaldo Sant'Anna. Rio de Janeiro: Civilização Brasileira, 2011. (Livro 1, v. 1).

MOTA, A. E. A centralidade da assistência social na Seguridade Social brasileira nos anos 2000. In: MOTA, A. E. (Org.). $O$ mito da assistência social: ensaios sobre Estado, política e sociedade. São Paulo: Cortez, 2008, cap. 1, p. 133-177.

; AMARAL, A. S. do. Reestruturação do capital, fragmentação do trabalho e Serviço Social. In: MOTA, A. E. (Org.). A nova fábrica de consensos. São Paulo: Cortez, 2008, cap. 1, p. 28.

OLIVEIRA, F. de. Crítica à razão dualista: o ornitorrinco. São Paulo: Boitempo, 2011.

\section{Notas}

1 Aqui, apoiamo-nos no entendimento de que força de trabalho ou capacidade de trabalhoé "o conjunto das faculdades físicas e mentais existentes no corpo e na personalidade viva de um ser humano, as quais ele põe em ação toda vez que produz valores-de-uso de qualquer espécie" (MARX, 2011, p. 197).

2 Morfologia compreendida a partir do (novo) caráter multifacetado do trabalho (ANTUNES, 2005).

3 Evidenciamos algumas conquistas como a Lei para a reparação dos acidentes de trabalho em 1919 e a criação da Consolidação das Leis do Trabalho (CLT) em 1943; esta última foi criada para regular as relações individuais e coletivas de trabalho, unificando toda a legislação trabalhista até então existente no Brasil.

\section{Aurora Marcionila de Assunção Ferreira}

auroraassuncao@hotmail.com

Mestre em Serviço Social pela Universidade Federal de Pernambuco (UFPE)

Assistente Social do Hospital das Clínicas da UFPE

\section{UFPE - Hospital das Clínicas}

Av. Professor Moraes Rego, s/n

Cidade Universitária

Recife - Pernambuco - Brasil

CEP: 50670-420

\section{Angela Santana do Amaral}

angelaufpe@yahoo.com.br

Doutora em Serviço Social pela Universidade Federal do Rio de Janeiro (UFRJ)

Professora do Departamento de Serviço Social da UFPE

\section{UFPE - DSS}

Av. dos Economistas, s/n

Cidade Universitária

Recife - Pernambuco - Brasil

CEP: 50670-901 